\title{
Can serum 8-hydroxy-2'-deoxyguanosine levels reflect the severity of pulmonary arterial hypertension?
}

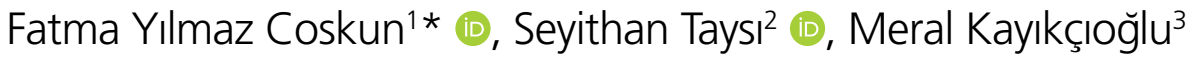

\begin{abstract}
SUMMARY
OBJECTIVE: Oxidative stress plays a pivotal role in the pathogenesis of pulmonary arterial hypertension. 8-Hydroxy-2'-deoxyguanosine is a sensitive biomarker that reflects the degree of oxidative damage to DNA. We investigated whether serum 8-Hydroxy-2'-deoxyguanosine is a clinically useful biomarker for the severity of pulmonary arterial hypertension.

METHODS: We measured serum 8-Hydroxy-2'-deoxyguanosine levels in 25 patients (age 37+13 years, 68\% women) diagnosed with idiopathic pulmonary arterial hypertension, familial pulmonary arterial hypertension, or pulmonary arterial hypertension associated with congenital heart disease. The severity of pulmonary arterial hypertension was evaluated by six-min walking distance, World Health Organization functional class, and serum brain natriuretic peptide levels. Age and gender-matched 22 healthy subjects served as the control group.

RESULTS: The comparison of 8-Hydroxy-2'-deoxyguanosine levels between patients and controls was not statistically different [(19.86 \pm 9.79$)$ versus (18.80 \pm 3.94$) \mathrm{ng} / \mathrm{mL}, \mathrm{p}=0.622)]$. However, there was a significant negative correlation between 8-Hydroxy-2'-deoxyguanosine levels and six-min walking distance $(r=-0.614, p=0.001)$. Additionally, serum 8 -Hydroxy-2'-deoxyguanosine levels in patients with functional class III-IV were significantly higher than those with functional class I-II (functional class III-IV $32.31 \pm 10.63 \mathrm{ng} / \mathrm{mL}$ versus functional class I-II $16.74 \pm 6.81 \mathrm{ng} / \mathrm{mL}$, respectively, $\mathrm{p}=0.003)$.

CONCLUSION: The 8-Hydroxy-2'-deoxyguanosine levels were significantly correlated with exercise capacity (six-min walking distance) and symptomatic status (functional class), both of which show the severity of pulmonary arterial hypertension in patients.

KEYWORDS: 8-Hydroxy-2'-deoxyguanosine. Pulmonary arterial hypertension. Oxidative stress.
\end{abstract}

\section{INTRODUCTION}

Pulmonary arterial hypertension $(\mathrm{PAH})$ is a severe clinical condition characterized by progressive obstructive remodeling of the distal pulmonary arteries resulting in a rise of pulmonary artery pressure and pulmonary vascular resistance (PVR) and subsequently leading to right heart failure and premature death unless treated ${ }^{1}$.

The pathophysiology of PAH is a very complex process that is still not well understood. Genetic and environmental factors can initiate the pathologic process in pulmonary vascular remodeling. These changes involve pulmonary endothelial dysfunction, maladapted immunity, inflammation, proliferation, and phenotypic alterations of pulmonary vascular cells. Particularly, current evidence indicates that inflammation and increased oxidative status play a major role in mediating vascular remodeling and $\mathrm{PAH}$ progression $^{2}$. Increased oxidative stress promotes oxidative damage to cellular components such as proteins, lipids, and DNA. It has been shown that DNA damage is increased in human remodeled pulmonary arteries such as pulmonary artery smooth muscle cells (PA-SMCs) and pulmonary artery endothelial cells (PA-ECs) in explanted lungs of patients with $\mathrm{PAH}^{3}$. Furthermore, increased DNA damage and/or impaired DNA repair are considered to be the potential stimulators of the proliferative and apoptosis-resistant phenotype, which is described in vascular remodeling of PAH.

\footnotetext{
${ }^{1}$ Gaziantep University Medical Faculty, Department of Cardiology - Gaziantep, Turkey.

${ }^{2}$ Gaziantep University Medical Faculty, Department of Biochemistry - Gaziantep, Turkey.

${ }^{3}$ Ege University Medical Faculty, Department of Cardiology - Izmir, Turkey.

*Corresponding author: ftm1981@yahoo.com

Conflicts of interest: the authors declare there are no conflicts of interest. Funding: none.

Received on July 02, 2021. Accepted on July 18, 2021.
} 
8-Hydroxy-2'-deoxyguanosine (8-OHdG) is the most commonly found oxidative DNA damage product in humans. This oxidative, modified DNA product has extensively been investigated as a marker of the degree of oxidative damage to DNA due to its stability. The increased levels of 8-OHdG are associated with carcinogenesis, cardiovascular disease, and diabetes ${ }^{4}$.

To the best of our knowledge, there are no data regarding the DNA damage marker and its relation with the severity of patients with PAH. Thus, we aimed to evaluate the serum 8-OHdG levels and their association with the severity of disease in patients with PAH.

\section{METHODS}

\section{Study population}

Patients aged 18 or older and previously diagnosed with idiopathic PAH (IPAH), familial PAH (FPAH), and PAH associated with congenital heart disease (CHD) by right heart catheterization in our center were included in the study. PAH was defined as mean pulmonary artery pressure over $25 \mathrm{mmHg}$, pulmonary artery wedge pressure (PAWP) $£ 15 \mathrm{mmHg}$, and $\mathrm{PVR}^{3} 3$ wood units. Considering the possible increase of oxidative DNA damage in chronic diseases, $\mathrm{PAH}$ subgroups associated with chronic diseases (i.e., connective tissue disease, HIV infection, and portal hypertension) and drug-toxin-associated $\mathrm{PAH}$ were not included in the study $\mathrm{y}^{5-7}$. Other exclusion criteria were pulmonary veno-occlusive disease/pulmonary capillary hemangiomatosis, pulmonary hypertension $(\mathrm{PH})$ due to left heart disease, $\mathrm{PH}$ due to lung diseases and/or hypoxia, chronic thromboembolic and/or other pulmonary artery obstructions with $\mathrm{PH}$ and $\mathrm{PH}$ with unclear or multifactorial mechanisms, history of chronic disease, abnormal renal function (creatinine $>1.5 \mathrm{mg} / \mathrm{dL}$ ), abnormal liver functions, acute infections, and neoplasia. Consequently, 25 patients who met the inclusion criteria were enrolled in the study. Age and gender-matched 22 healthy individuals served as the control group who had no medical history of any chronic disease and no abnormal findings in blood tests and transthoracic echocardiography. Patients were classified into three groups according to the $\mathrm{WHO}$ functional classification (FC) criteria as follows: FC I-II, FC III, and FC IV. A six-min walk distance (6MWD) was performed according to the standard protocol ${ }^{8}$. Ethical approval was obtained from the local Ethics Committee ( $N^{\circ}$ 2018/333). Informed written consent was provided from all subjects.

\section{Echocardiographic assessment}

Two-dimensional, M-mode, tissue Doppler imaging (TDI), spectral, and color flow Doppler echocardiographic assessments were performed using Vivid E9, 2-4 MHz phased-array transducer (General Electric, USA) in all patients and control subjects. Chambers' quantification and function were evaluated according to the recommendation of the American Society of Echocardiography and the European Association of Cardiovascular Imaging Guidelines. Right ventricular (RV) function was evaluated using tricuspid annular plane systolic excursion (TAPSE), TDI-derived tricuspid lateral annular systolic velocity wave (RV-S'), and RV fractional area changing (FAC) from RV-focused apical four-chamber view. The estimated RV systolic pressure was calculated using the maximum tricuspid regurgitation jet and the estimation of RA pressure based on inferior vena cava size and collapsibility. Left ventricular ejection fraction (LVEF) was calculated using biplane modified Simpson's rule?.

\section{Blood sampling for 8-Hydroxy-2'- deoxyguanosine measurement}

Blood samples were obtained from a peripheral vein after an overnight fasting and 10-min rest period for the measurements of 8-OHdG, brain natriuretic peptide (BNP), and other basic biochemical variables. Samples were kept frozen at $-80^{\circ} \mathrm{C}$ if not analyzed immediately. Serum 8 -OHdG measurement was made using the Elx 800 instrument (BioTek Instruments, Winooski, VT, USA) with a commercial competitive enzymelinked immunosorbent assay (ELISA) kit (Northwest, NWLSS 8-OHdG ELISA High Sensitivity Kit, Vancouver, Canada), which expressed as $\mathrm{ng} / \mathrm{ml}$. The plasma levels of $8-\mathrm{OHdG}$, echocardiographic variables, and basic characteristics were compared between the groups. The correlation between the plasma levels of 8-OHdG and 6MWD, BNP, and echocardiographic measurements were investigated among patients. Also, 8-OHdG levels were compared across patients' groups classified according to FC.

\section{Statistical evaluation}

SPSS version 20.0 software was used for the statistical analysis. The Student's $t$-test was used for the comparison of parametric qualitative variables between the PAH and control groups. Pearson's correlation analysis was used to assess correlations between continuous variables with normal distribution, and Spearman's rank test was used for the variables with skewed distribution. A p $<0.05$ (two-sided) was considered statistically significant.

\section{RESULTS}

Baseline characteristics and echocardiographic measurements of the patient group $(n=25)$ are presented in Table 1 . The mean age of the patients was $37 \pm 13$ years, and $68 \%$ of them were females. 
Table 1. Characteristics of patients $(n=25)$.

\begin{tabular}{|c|c|}
\hline Demographics & \\
\hline Age (year) & $37 \pm 13$ \\
\hline Sex (female/male) & $17 / 8$ \\
\hline BMI $\left(\mathrm{kg} / \mathrm{m}^{2}\right)$ & $24.3 \pm 4.7$ \\
\hline Diagnosis [n (\%)] & \\
\hline IPAH & $5(20)$ \\
\hline FPAH & $1(4)$ \\
\hline PAH associated with CHD & $19(76)$ \\
\hline Clinical Findings & \\
\hline $6 \mathrm{MWD}(\mathrm{m})$ & $371.0 \pm 146.6$ \\
\hline WHO Functional Class [n (\%)] & \\
\hline FC I-II & $20(80)$ \\
\hline FC III-IV & $5(20)$ \\
\hline $\begin{array}{l}\text { Clinical signs of right heart failure [n } \\
(\%)]\end{array}$ & $6(24)$ \\
\hline Syncope [n (\%)] & $1(4)$ \\
\hline Heart rhythm [n (\%)] & \\
\hline SR & $20(80)$ \\
\hline AF & $5(20)$ \\
\hline Laboratory Findings & \\
\hline Hemoglobin (g/dL) & $14.1 \pm 2.9$ \\
\hline Leukocyte $\left(10^{3} / \mathrm{mL}\right)$ & $7.431 \pm 2.026$ \\
\hline Platelet $\left(10^{3} / \mathrm{mL}\right)$ & $230 \pm 61$ \\
\hline Creatinine (mg/dL) & $0.72 \pm 0.22$ \\
\hline AST (U/L) & $24 \pm 7$ \\
\hline $\operatorname{ALT}(\mathrm{U} / \mathrm{L})$ & $15 \pm 8$ \\
\hline Uric acid (mg/dL) & $5.7 \pm 2.2$ \\
\hline Medications [n (\%)] & \\
\hline $\begin{array}{l}\text { ERA } \\
\text { Bosentan/Macitentan/Ambrisentan }\end{array}$ & $\begin{array}{l}25(100) \\
5(20) / 19 \\
(76) / 1(4)\end{array}$ \\
\hline $\begin{array}{l}\text { PDEI } \\
\text { Sildenafil/Tadalafil }\end{array}$ & $\begin{array}{c}18(72) \\
7(28) / 11(44)\end{array}$ \\
\hline Prostacyclin analogs & $2(8)$ \\
\hline Diuretic & $9(36)$ \\
\hline Calcium channel blocker & $4(16)$ \\
\hline Beta-blocker & $6(24)$ \\
\hline Digoxin & $3(12)$ \\
\hline Warfarin or DOAC & $4(16)$ \\
\hline
\end{tabular}

BMI: body mass index; PAH: pulmonary arterial hypertension; IPAH: idiopathic PAH; FPAH: Familial PAH; CHD: congenital heart disease; 6MWD: six-min walking distance; FC: functional class; SR: sinus rhythm; AF: atrial fibrillation; AST: aspartate transaminase; ALT: alanine transaminase; ERA: endothelin receptor antagonist; PDEl: phosphodiesterase inhibitor; DOAC: direct oral anticoagulant.
Almost $80 \%$ were PAH associated with CHD. Meanwhile, most of them were in FC I or II, and only $24 \%$ had symptoms of right heart failure.

Table 2 shows the comparison of the groups. The comparison of 8-OHdG levels between patients and controls was not statistically different $[(19.86 \pm 9.79)$ versus $(18.80 \pm 3.94)$ $\mathrm{ng} / \mathrm{mL}$, respectively, $\mathrm{p}=0.622)]$. Moreover, the comparison of 8-OHdG levels between patients' subgroups (IPAH/FPAH and PAH associated with CHD) was also not statistically different [(14.72 \pm 4.81$)$ versus $(21.48 \pm 10.48) \mathrm{ng} / \mathrm{mL}$, respectively, $\mathrm{p}=0.144)]$. However, the levels of $8-\mathrm{OHdG}$ levels were negatively correlated with 6MWD ( $\mathrm{r}=-0.614, \mathrm{p}=0.001)$ (Table 3). Furthermore, the serum 8-OHdG levels in patients with FC III-IV were significantly higher than those with FC I-II (FC III-IV $32.31 \pm 10.63 \mathrm{ng} / \mathrm{mL}$ versus FC I-II $16.74 \pm 6.81 \mathrm{ng} / \mathrm{mL}$, respectively, $\mathrm{p}=0.003$ ) (Figure 1 ).

The BNP levels were significantly higher in patients compared to control (175.75 \pm 76.45 versus $15.16 \pm 1.79 \mathrm{ng} / \mathrm{mL}$; $\mathrm{p}=0.002)$ and showed significantly negative correlation with 6MWD ( $\mathrm{r}=-0.506, \mathrm{p}=0.010)$ (Table 3). Also, serum BNP levels in patients with FC III-IV were significantly higher than those with FC I-II (FC III-IV: $628.00 \pm 720.41 \mathrm{ng} / \mathrm{mL}$ versus FC I-II $62.69 \pm 89.64 \mathrm{ng} / \mathrm{mL}$, respectively, $\mathrm{p}=0.042$ ). There was no association between 8-OHdG and BNP levels.

\section{DISCUSSION}

Our results showed that serum 8-OHdG levels, a marker of DNA damage, were increased significantly in parallel to the severity of FC and negatively correlated with 6MWD among patients with PAH. Both FC and 6MWD are used as noninvasive risk tools for disease severity and risk prediction of mortality of patients with PAH in current risk-scoring systems. They are powerful predictors of survival and correlated with the severity of disease at diagnosis and also during follow-up in $\mathrm{PAH}^{10}$.

DNA damage has been previously shown to be increased in the lungs of patients with PAH, remodeled arteries, PA-SMCs, and PA-ECs ${ }^{11}$. Furthermore, the oxidative stress that is believed to play a crucial role in the development and progression of vascular remodeling in PAH could also promote DNA damage ${ }^{12}$. Although DNA damage and intrinsic mutagen sensitivity have been shown to increase in $\mathrm{PAH}^{3}$, to the best of our knowledge, there is no study to evaluate the serum DNA damage markers and disease severity in these patient populations so far.

The assessment of the severity of $\mathrm{PAH}$ poses special importance because it is used for guiding medical therapy and determining the timing of lung transplantation. Therefore, numerous biomarkers as noninvasive parameters have been extensively investigated $^{13}$. These markers might be classified as markers of 
Table 2. Comparison of basal characteristics, serum brain natriuretic peptide and 8-OHdG levels, and echocardiographic parameters between patients and controls.

\begin{tabular}{l|c|c|c} 
& Patients $(\mathrm{n}=25)$ & Control $(\mathrm{n}=22)$ & $\mathrm{p}$-value \\
\hline Age $($ year $)$ & $37.4 \pm 13.6$ & $35.8 \pm 8.3$ & 0.614 \\
\hline Gender $(\mathrm{female} / \mathrm{male})$ & $17 / 8$ & $14 / 8$ & 0.763 \\
\hline BMI $\left(\mathrm{kg} / \mathrm{m}^{2}\right)$ & $24.3 \pm 4.7$ & $25.3 \pm 3.7$ & 0.469 \\
\hline $8-\mathrm{OHdG}(\mathrm{ng} / \mathrm{mL})$ & $19.86 \pm 9.79$ & $18.80 \pm 3.94$ & 0.622 \\
\hline BNP & $175.75 \pm 76.45$ & $15.16 \pm 1.79$ & 0.002 \\
\hline TRV $(\mathrm{m} / \mathrm{s})$ & $3.82 \pm 1.20$ & $1.00 \pm 1.07$ & $<0.001$ \\
\hline SPAP $(\mathrm{mmHg})$ & $72.50 \pm 7.80$ & $9.54 \pm 2.37$ & $<0.001$ \\
\hline RV-FAC $(\%)$ & $34.52 \pm 9.92$ & $49.68 \pm 7.53$ & $<0.001$ \\
\hline RV annular peak velocity $(\mathrm{cm} / \mathrm{s})$ & $12.08 \pm 3.49$ & $14.18 \pm 2.19$ & 0.017 \\
\hline TAPSE $(\mathrm{mm})$ & $18.24 \pm 3.58$ & $23.77 \pm 4.29$ & $<0.001$ \\
\hline LV-Eccentricity index & $1.46 \pm 0.28$ & $0.98 \pm 0.08$ & $<0.001$ \\
\hline RV/LV basal diameter ratio & $1.29 \pm 0.28$ & $0.75 \pm 0.08$ & $<0.001$ \\
\hline RA area $\left(\mathrm{cm}^{2}\right)$ & $26.98 \pm 3.57$ & $12.00 \pm 2.38$ & $<0.001$ \\
\hline PA $(\mathrm{mm})$ & $31.84 \pm 6.69$ & $21.19 \pm 2.31$ & $<0.001$ \\
\hline LVEF $(\%)$ & $65.04 \pm 5.45$ & $65.18 \pm 6.44$ & 0.936 \\
\hline
\end{tabular}

BMI: body mass index; BNP: brain natriuretic peptide; TRV: tricuspid regurgitation max velocity; SPAP: systolic pulmonary artery pressure; RV-FAC: right ventricular-fractional area change; TAPSE: tricuspid annular plane systolic excursion; LV: left ventricle; RA: right atrium; PA: pulmonary artery; LVEF: left ventricular ejection fraction.

Table 3. Correlation between 8-Hydroxy-2'-deoxyguanosine levels and 6-min walking distance, brain natriuretic peptide, and echocardiographic parameters.

\begin{tabular}{l|c|c}
\multirow{2}{*}{} & \multicolumn{2}{c}{ 8-Hydroxy-2'-deoxyguanosine } \\
\cline { 2 - 3 } 6MWD & $r$ & p-value \\
\hline BNP & -0.614 & 0.001 \\
\hline TRV & 0.341 & 0.095 \\
\hline SPAP & 0.228 & 0.284 \\
\hline RV-FAC & 0.292 & 0.166 \\
\hline RV annular peak & -0.051 & 0.810 \\
systolic velocity & -0.047 & 0.824 \\
\hline TAPSE & -0.117 & 0.579 \\
\hline RA area & 0.308 & 0.144 \\
\hline PA & 0.423 & 0.035 \\
\hline
\end{tabular}

6MWD: 6-min walking distance; BNP: brain natriuretic peptide; TRV: tricuspid regurgitation max velocity; SPAP: systolic pulmonary artery pressure; RVFAC: right ventricular-fractional area change; TAPSE: tricuspid annular plane systolic excursion; LV: left ventricle; RA: right atrium; PA: pulmonary artery

vascular dysfunction, inflammation, myocardial stress, and low cardiac output and/or tissue hypoxia. 8-OHdG is a stable biomarker of oxidative damage to DNA that has been shown to be correlated with the severity of several cardiovascular diseases ${ }^{14,15}$.

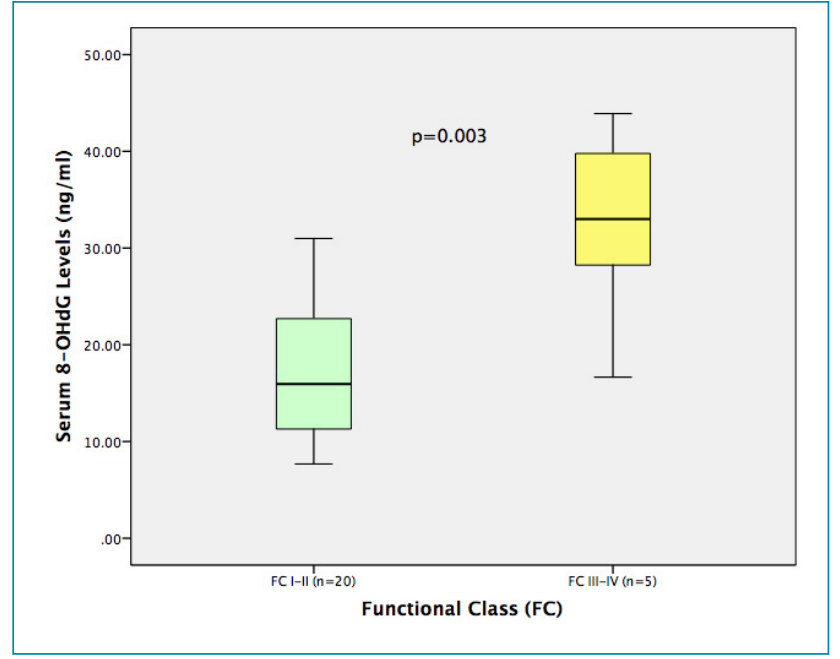

Figure 1. Relationship between serum 8-Hydroxy-2'deoxyguanosine levels and World Health Organization functional classification among patients with pulmonary arterial hypertension.

Regarding PAH, only one study from Bowers et al. has shown that plexiform lesions and luminal endothelial cells of concentric intimal fibrosis lesions of explanted lungs of patients with IPAH were intensely stained by $8-\mathrm{OHdG}$, which is indicating the presence of DNA oxidation ${ }^{16}$. BNP and NT-proBNP, which correlate with myocardial dysfunction, are the most commonly 
used validated biomarkers in PAH. In line with our results, these markers also provide information regarding disease severity and prognosis during the diagnosis and follow-up of these patients ${ }^{17}$. Contrary to expectation, there was no correlation between 8-OHdG levels and BNP levels even though they both correlated with the clinical severity of patients in our study. It could be related to different characteristics of these two biomarkers. BNP is mainly secreted from the cardiomyocytes in response to cardiac stretch, and its levels can range widely in short time periods, according to volume status and treatments in patients with heart failure ${ }^{18}$. In contrast, $8-\mathrm{OHdG}$ is a stable marker of oxidative DNA damage, and it seems to reflect an established pathophysiological status ${ }^{19}$; therefore, its levels may not show changes parallel to BNP under acute circumstances.

Some issues and limitations should be pointed out while interpreting our findings. Although on the ground of the knowledge that $8-\mathrm{OHdG}$ is a marker reflecting the degree of oxidative damage to DNA, we could not show any statistical difference regarding the 8-OHdG levels between patients and controls. It could possibly be explained with several reasons. First, a relatively small sample size of the study due to being conducted in a single center may have affected the statistical analysis. Second, $80 \%$ of the patients in our study were clinically stable, and their functional class was FC I-II. Studies have shown that there is a negative correlation between patient functional capacity and oxidative status of patients with $\mathrm{PAH}^{13,20}$. Third, $\mathrm{PAH}$ is associated with CHD, which is comprised of $76 \%$ of our study population, even if it shows similar histological features with IPAH, the role of inflammation in its pathogenesis remains controversial ${ }^{21}$. Another worth mentioning point is that the anti-inflammatory effects of PAH-specific treatments are known; however, the evaluation of their effects on oxidative DNA damage and subsequently on 8-OHdG levels could not be possible as there was no treatment naïve patient in our study ${ }^{22}$. Considering these factors mentioned above, the possible low oxidative status of most of our patient population could partly explain the nonsignificant difference of serum 8-OHdG levels between the patients with PAH and the controls. However, it can hardly go beyond speculation.

\section{CONCLUSION}

The serum 8-OHdG level that is an oxidative DNA damage marker significantly correlated with exercise capacity (6MWD) and symptomatic status (FC) of the patients with PAH. However, the abovementioned multiple factors, which may have affected the results of the study, could not be excluded. 8-OHdG might be a potential candidate as a noninvasive parameter for the classification of severity of the patients with $\mathrm{PAH}$; however, it requires further research.

\section{AUTHORS' CONTRIBUTIONS}

FYC: Conceptualization, Data curation, Formal analysis, Project administration, Writing - original draft, Writing - review \& editing. ST: Conceptualization, Data curation, Writing - review \& editing. MK: Conceptualization, Formal analysis, Writing - original draft, And Writing - review \& editing.

\section{REFERENCES}

1. Simonneau G, Montani D, Celermajer DS, Denton $C P$, Gatzoulis MA, Krowka M, et al. Haemodynamic definitions and updated clinical classification of pulmonary hypertension. Eur Respir J. 2019;53(1):1801913. https://doi. org/10.1183/13993003.01913-2018

2. Luna RCP, Oliveira Y, Lisboa JVC, Chaves TR, Araujo TAM, Sousa EE, et al. Insights on the epigenetic mechanisms underlying pulmonary arterial hypertension. Braz J Med Biol Res. 2018;51(12):e7437. https://doi.org/10.1590/1414$431 \times 20187437$

3. Federici C, Drake KM, Rigelsky CM, McNelly LN, Meade SL, Comhair SA, et al. Increased mutagen sensitivity and DNA damage in pulmonary arterial hypertension. Am J Respir Crit Care Med. 2015;192(2):219-28. https://doi.org/10.1164/ rccm.201411-21280C4

4. Wu LL, Chiou CC, Chang PY, Wu JT. Urinary 8-OHdG: a marker of oxidative stress to DNA and a risk factor for cancer, atherosclerosis and diabetics. Clin Chim Acta. 2004;339(12):1-9. https://doi.org/10.1016/j.cccn.2003.09.010
5. Simenauer A, Nozik-Grayck E, Cota-Gomez A. The DNA damage response and HIV-associated pulmonary arterial hypertension. Int J Mol Sci. 2020;21(9):3305. https://doi. org/10.3390/ijms21093305

6. Grossi S, Sumberaz A, Gosmar M, Mattioli F, Testino G, Martelli A. DNA damage in peripheral blood lymphocytes of patients with cirrhosis related to alcohol abuse or to hepatitis B and C viruses. Eur J Gastroenterol Hepatol. 2008;20(1):22-5. https:// doi.org/10.1097/MEG.0b013e3282f163fe

7. Chen PI, Cao A, Miyagawa K, Tojais NF, Hennigs JK, Li CG, et al. Amphetamines promote mitochondrial dysfunction and DNA damage in pulmonary hypertension. JCI Insight. 2017;2(2):e90427. https://doi.org/10.1172/ jci.insight. 90427

8. ATS Committee on Proficiency Standards for Clinical Pulmonary Function Laboratories. ATS statement: guidelines for the six-minute walk test. Am J Respir Crit Care Med. 2002;166(1):111-7. https://doi.org/10.1164/ ajrccm.166.1.at1102 
9. Lang RM, Badano LP, Mor-Avi V, Afilalo J, Armstrong A, Ernande $L$, et al. Recommendations for cardiac chamber quantification by echocardiography in adults: an update from the American Society of Echocardiography and the European Association of Cardiovascular Imaging. J Am Soc Echocardiogr. 2015;28(1):1-39.e14. https://doi.org/10.1016/j. echo.2014.10.003

10. Hoeper MM, Pittrow D, Opitz C, Gibbs JSR, Rosenkranz $S$, Grünig $E$, et al. Risk assessment in pulmonary arterial hypertension. Eur Respir J. 2018;51(3):1702606. https://doi. org/10.1183/13993003.02606-2017

11. Mutlu Z, Kayıkçıoğlu M, Nalbantgil S, Vuran Ö, Kemal H, Moğulkoç N, et al. Sequencing of mutations in the serine/ threonine kinase domain of the bone morphogenetic protein receptor type 2 gene causing pulmonary arterial hypertension. Anatol J Cardiol. 2016;16(7):491-6. https://doi.org/10.5152/ AnatolJCardiol.2015.6297

12. Rafikova O, Rafikov R, Kangath A, Qu N, Aggarwal S, Sharma $S$, et al. Redox regulation of epidermal growth factor receptor signaling during the development of pulmonary hypertension. Free Radic Biol Med. 2016;95:96-111. https://doi.org/10.1016/j. freeradbiomed.2016.02.029

13. Warwick $G$, Thomas PS, Yates $D H$. Biomarkers in pulmonary hypertension. Eur Respir J. 2008;32(2):503-12. https://doi. org/10.1183/09031936.00160307

14. Xiang F, Shuanglun $X$, Jingfeng $W$, Ruqiong $N$, Yuan Z, Yongqing $L$, et al. Association of serum 8-hydroxy-2'-deoxyguanosine levels with the presence and severity of coronary artery disease. Coron Artery Dis. 2011;22(4):223-7. https://doi.org/10.1097/ MCA.0b013e328344b615

15. Loffredo L, Pignatelli P, Cangemi R, Andreozzi P, Panico MA, Meloni $\mathrm{V}$, et al. Imbalance between nitric oxide generation and oxidative stress in patients with peripheral arterial disease: effect of an antioxidant treatment. J Vasc Surg. 2006;44(3):525-30. https://doi.org/10.1016/j.jvs.2006.05.023
16. Bowers R, Cool C, Murphy RC, Tuder RM, Hopken MW, Flores SC, et al. Oxidative stress in severe pulmonary hypertension. Am J Respir Crit Care Med. 2004;169(6):764-9. https://doi. org/10.1164/rccm.200301-1470C

17. Galie N, Humbert M, Vachiery JL, Gibbs S, Lang I, Torbicki A, et al. 2015 ESC/ERS Guidelines for the diagnosis and treatment of pulmonary hypertension: the joint task force for the diagnosis and treatment of pulmonary hypertension of the European Society of Cardiology (ESC) and the European Respiratory Society (ERS): Endorsed by: Association for European Paediatric and Congenital Cardiology (AEPC), International Society for Heart and Lung Transplantation (ISHLT). Eur Heart J. 2016;37(1):67-119. https://doi.org/10.1093/eurheartj/ehv317

18. Cao Z, Jia Y, Zhu B. BNP and NT-proBNP as Diagnostic Biomarkers for Cardiac Dysfunction in Both Clinical and Forensic Medicine. Int J Mol Sci. 2019;20(8):1820. https:// doi.org/10.3390/ijms20081820

19. Bautista-Nino PK, Portilla-Fernandez E, Vaughan DE, Danser $\mathrm{AH}$, Roks AJ. DNA damage: a main determinant of vascular aging. Int J Mol Sci. 2016;17(5):748. https://doi.org/10.3390/ ijms17050748

20. Anwar A, Ruffenach G, Mahajan A, Eghbali M, Umar S. Novel biomarkers for pulmonary arterial hypertension. Respir Res. 2016;17(1):88. https://doi.org/10.1186/s12931-016-0396-6

21. Low A, George S, Howard L, Bell N, Millar A, Tulloh RMR. Lung function, inflammation, and endothelin-1 in congenital heart disease-associated pulmonary arterial hypertension. J Am Heart Assoc. 2018;7(4):e007249. https://doi.org/10.1161/ JAHA. 117.007249

22. Steven S, Oelze M, Hausding M, Roohani S, Kashani F, KrollerSchon $S$, et al. The endothelin receptor antagonist macitentan improves Isosorbide-5-Mononitrate (ISMN) and Isosorbide Dinitrate (ISDN) induced endothelial dysfunction, oxidative stress, and vascular inflammation. Oxid Med Cell Longev. 2018;2018:7845629. https://doi.org/10.1155/2018/7845629 